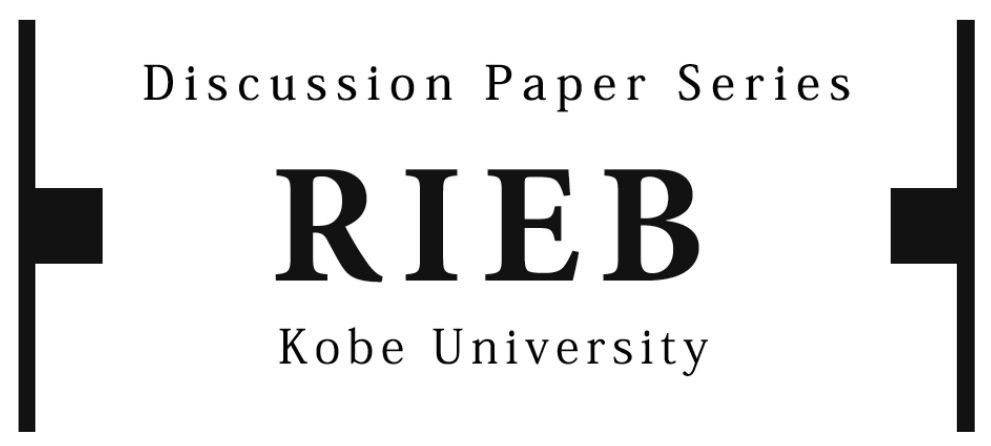

DP2011-33

\title{
Food Price Surges and Poverty in Urban Colombia: New Evidence from Household Survey Data*
}

\section{Laura Kiku RODRIGUEZ-TAKEUCHI}

Katsushi S. IMAI

December 5, 2011

* The Discussion Papers are a series of research papers in their draft form, circulated to encourage discussion and comment. Citation and use of such a paper should take account of its provisional character. In some cases, a written consent of the author may be required.

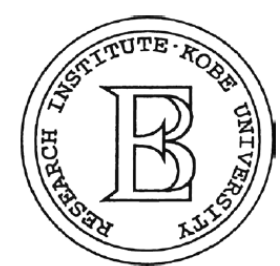

Research Institute for Economics and Business Administration Kobe University 


\title{
Food Price Surges and Poverty in Urban Colombia: New Evidence from Household Survey Data
}

\author{
Laura Kiku Rodriguez-Takeuchi
}

\&

\author{
Katsushi S. Imai * \\ School of Social Sciences, University of Manchester, UK and \\ Research Institute for Economics \& Business Administration (RIEB), \\ Kobe University, Japan
}

$5^{\text {th }}$ December 2011

\begin{abstract}
The present study simulates the impacts of price surges in 2006-2008 on household poverty in the main Colombian cities. It is found that the price surges increased both extreme and moderate poverty in urban areas in short and medium terms. However, the magnitude of poverty rise is not homogeneous geographically or by household types e.g., the poorest or less educated households were more badly affected than the wealthier or educated households. We suggest 'demographic targeting' or 'geographical targeting' as a policy option that selects and supports poor households by demographic characteristics or by geographical areas according to the degree of vulnerability. Protecting those households from food price shocks would be still important now given that rising and volatile food prices have continued due to erratic climate patterns and demand and supply conditions along with economic and financial crisis.
\end{abstract}

Keywords: food price surges, urban poverty, Colombia

JEL Codes: C21, I32, O15, O54

\section{*Corresponding Author:}

Katsushi S. Imai (Dr)

Economics, School of Social Sciences

University of Manchester, Arthur Lewis Building,

Oxford Road, Manchester M13 9PL, UK

Phone: +44-(0)161-275-4827

Fax: +44-(0)161-275-4928

E-mail: Katsushi.Imai@manchester.ac.uk

\section{Acknowledgements}

The authors greatly appreciate comments and advice from Patricia Cabrerizo, Maria del Carmen Franco, Raghav Gaiha, and Juan Villa Lora. Only the authors are responsible for any errors. 


\section{Food Price Surges and Poverty in Urban Colombia: New Evidence from Household Survey Data}

\section{Introduction}

From 2007 till the second quarter of 2008 international prices of basic staples experienced major increases reflecting oil price surges. After the fall in late 2008 to early 2009, prices of major commodities, such as cereals, oilseeds, meat have shown increasing trends till early 2011 and high prices are expected in the near future (FAO, 2011a, b). In particular, large and unexpected price movements are likely to be harmful to people's living standards, particularly in developing countries (FAO, 2011b). Social and economic outcomes of food price are serious in developing countries - ranging from riots and protests, increases in poverty, hunger and malnutrition (FAO, 2008a) to decline in investment in research, physical and human capital (Prakash, 2010) and in aid flows the augmented cost of food aid programs (Oxfam, 2011).

The head of the World Food Program called the price surge episode the 'silent tsunami of hunger' (Sheeran, 2011) and this was not a problem of shortages. Different voices (e.g. Banerjee and Duflo, 2011) called the attention to the fact that there is enough food to feed the entire world population. Hunger is not of a situation where there is not food but one where some people do not have enough food and thus how people get entitlement and access to it is important (Sen, 1980).

The extent to which people are affected by food price surges depends on whether they are net food producers or consumers (Ivanic and Martin, 2008). It is surmised in this context that poor people in urban areas were more vulnerable to recent price surges and that their household budgets were directly affected by a trade entitlement failure streaming from an endowment loss or a deterioration of terms of trade (Sen, 1980, 1999). When those people purchase food, their ability to fulfill the right of being free from hunger is limited by 
precarious wages and employment, as well as discrimination in access to economic resources, market places and the absence or malfunctioning of social security nets to provide a cushion for hardship situations (High Commissioner for Human Rights \& FAO, 2010).

Despite the importance of the issue and policy debates, there have been few rigorous to evaluate the recent price surges on poverty or hunger of households in developing countries with a few exceptions (e.g., Ivanic \& Martin, 2008; de Janvry and Sadoulet, 2010; Leyaro et al., 2010; Thurlow et al., 2011). The present study attempts to fill the gap by estimating the effects of recent food price surges on expenditure and poverty of urban households in Colombia where the food crisis was felt as well as the Central Bank missed the inflationary target largely as a result of high food prices. Methodologically, we follow de Janvry and Sadoulet, (2010) to simulate both short and medium term impacts of food price changes on expenditure based on the estimates for price elasticities for various food items to take into account demand responses of each household.

The rest of the paper is structured as follows. Section 2 provides a background for the food crisis and poverty in Colombia. Section 3 briefly explains the data and Section 4 surveys the past papers which analyzed the effects of price changes on household welfare in developing countries. Section 5 presents and discusses the methodology. The results of the estimations are reported in Section 6. Section 7 discusses possible policy options. The final section concludes with policy implications.

\section{Food price surge and poverty in Colombia}

Although overall inflation had been generally moderate till the end of 2006, afterwards the Central Bank of Colombia was under pressure as the inflation went much higher than the target range 3.5\%-4.5\% (Figure 1). In 2006-2008 annual changes of food CPI in Colombia 
(5.7\% in $2006 ; 8.5 \%$ in $2007 ; 13.2 \%)$ were much higher than those of general CPI $(4.5 \%$ in $2006 ; 5.7 \%$ in $2007 ; 7.7 \%$ in 2009) (DANE, 2011).

\section{[Figure 1 to be inserted around here]}

Several factors contributed to the transmission of the global food price surge in Colombia. First, international escalation of energy and oil prices in $2007-8$ raised transportation costs, input prices for agricultural production, and the prices of biofuel products, although revenues from exports were increased (BanRep, 2008). Second, the revaluation of the peso, along with increased food imports for local consumption, resulted in a reduction in the purchasing power of households. High demand for food items in Colombia and in neighboring Venezuela also contributed to price surges. Finally, extreme weather events had repercussions in agricultural production and food inflation in the first months of 2007 (BanRep, 2007).

Even though Colombia has a moderately low hunger problem (FAO, 2010), the fulfillment of the right to food is limited in other aspects; $40.8 \%$ of households are classified in National Nutritional State Survey-ENSIN as food insecure. ${ }^{1}$ Moreover, this survey showed a consistent correlation between food insecurity and poverty and with high food expenditures across different household structures, ethnicity, incomes, and place of residence (ICBF, 2005). Poor people in developing countries spend much more of their incomes on food (roughly 75 to 80 percent) than middle income people in industrialized countries (15 to 20 percent) (Brandt and Otzen, 2007). The negative relationship between disposable income and food expenditure share - Engel's law - can help explain why even temporary movements in prices have considerable negative effects on poor households. The higher the share of resources destined to food acquisition, the higher the risk of entitlement failure (Maxwell and

\footnotetext{
${ }^{1}$ Food insecurity is defined in the ENSIN following adaptations of international measures by Alvarez et al. (2006), in relation to the availability of money to buy food, the decrease in quantities or meals consumed and the experience of hunger by members of the household.
} 
Smith, 1992), even putting at risk for loss of health or life of the poorest in developing countries (Brandt and Otzen, 2007).

Engel's law is consistent with Colombian urban households' consumption pattern. Average food expenditures represent $27.72 \%$ of a household's monthly budget, whereas figures for the lowest and highest quintiles are 35.6 and $17.6 \%$ respectively. $^{2}$ The same pattern is observed for individual food items.

While the immediate effect of a price increase on households is loss in their purchasing power ceteris paribus, the price shock could have further consequences as the households adapt themselves for it, e.g., by selling assets, reducing the quantity, quality and variety of food consumed, or cutting other non-food expenditures such as health care and education (FAO, 2008a). Even if a price shock is short-lived, it could have a negative impact on household welfare in the long run (FAO, 2011b) as it may debilitates households' ability to respond to future distressful events in a self-reinforcing process. Thus, a failure that originates in the deterioration of the terms of trade easily translates into a weaker endowment position limiting the possibility to escape poverty.

\section{Data}

The present study requires the detailed and disaggregated price data as well as household food expenditure data. The food expenditure data is based on the National Survey of Incomes and Expenditures (ENIG) conducted in 2006-2007 by the Colombian National Statistical Department (DANE) in 296 municipalities. The present study uses only 14,695 households in 13 cities (out of 24 capital cities) in urban areas ${ }^{3}$.

\footnotetext{
${ }^{2}$ Authors' calculation based on the National Survey of Incomes and Expenditures Data.

${ }^{3} 13$ cities are Bogota, Medellin, Cali, Barranquilla, Bucaramanga, Cartagena, Cucuta, Manizales, Monteria, Neiva, Pasto, Pereira and Villavicencio. It is noted that the ENIG uses as a reference the census data in 1993 as a reference and our survey data are randomly sampled from 4,693,914 households (i.e. population).
} 
Local prices are taken from the CPI collected by DANE. Price data are matched with the food expenditure data for each household according to its location and the sampling month. We have used the CPI to calculate the variation over each food item and city during the 36 months comprising the 2006-2008 period.

Constrained by the availability of food price data, 13 major food items are used for our estimations. They are beef, chicken, fish pork, eggs, sugar, panela, cooking oils, dry legumes, rice, milk, and potatoes all of which (except pork) are among the most commonly consumed in the country (ICBF, 2005).

The variable of our interest is household poverty. Ravallion (1998) defines a poverty line as the minimum cost to achieve a reference welfare level. This cut-off point represents a subsistence base below which a human could not physically survive (e.g. UNDP, 2004) defining a poor person "as someone without enough to eat" (Banerjee and Duflo 2011, p.19), either directly measuring nutritional or caloric intake, or indirectly calculating the necessary income or expenditure to acquire that basket.

The present study uses the official Colombian lines for each city as poverty cut-off points, the reason being that as the level of aggregation increases information is inevitably lost thus it is better to use the most locally available information rather than a global absolute line (ECLAC, 2005; Srinivasan, 2001; Reddy, 2004). The construction of the extreme poverty line (EPL) in Colombia (Muñoz \& Rivas, 2006; MERPD, 2006) is based on a basic food consumption basket for the poorest population in each city evaluated at implicit values (unit values) and also at market prices for robustness $\operatorname{check}^{4}$. In addition, there is another poverty

\footnotetext{
${ }^{4}$ The criteria to include an item in the bundle to construct the EPL were five: either it was consumed by at least $30 \%$ of the households, accounted for $1 \%$ of the total food expenditure, contributed to at least $1 \%$ of the calories or proteins consumed, represented $0.5 \%$ of the total weight of food acquired by the households or 5\% of the subgroup of food items. Information on food quantities and corresponding monetary expenditure is recorded on a weekly basis using recording sheets handled to the households. When referring to food, the ENIG uses acquired consumption methodology which accounts for goods and services acquired in the reference period which could or could not been totally paid in the same period.
} 
line - Moderate Poverty Line (MPL) - intended to reflect the amount of money necessary to buy a bundle of basic commodities beyond food. This is constructed using a multiplier method; the EPL is multiplied by the inverse Engel coefficient (Oshansky coefficient). To make the poverty lines comparable with the household survey and track changes to make consumption comparisons, the official lines were adjusted using accumulated food CPI variation from September 2005 to September 2007 following the approach of ECLAC (2005) for each city. Household expenditures and the poverty lines for each city are all adjusted at 2007 values so that they are comparable. ${ }^{6}$

\section{Literature Survey}

In this section, we review selected studies which evaluated price surges on household welfare or poverty in the context of developing countries. Using 10 different sets of cross-sectional household survey data for 9 developing countries (e.g. Bolivia, Peru, Vietnam) in various periods (in 1998-2005), Ivanic and Martin (2008) simulated the possible effects of price surges in 2006-7 on aggregate poverty in those countries and found net food consumers tend to be hurt by food prices increases. However, the distinction between producer and consumer impacts which would be important for policy analysis (e.g. Chen and Ravallion, 2004) has not been taken into account in Ivanic and Martin's study due to the data constraints. Also,

\footnotetext{
${ }^{5}$ The Colombian government released in September 2011 a new methodology to calculate the poverty line. This updates the source for consumption patterns (2006-07 ENIG) and introduces a series of changes to the estimation procedure. The most relevant revisions include a common poverty threshold applied across all cities and urban areas, the change in the reference population from the poorest to the median population, the reduction of criterions of inclusion of a food item and the use of a fixed and exogenous Orshansky coefficient (see DNP, 2011 for details). However, the present study uses the national poverty lines which have been long used in the empirical literature of poverty studies on Colombia as (i) the use of the reference population based on the bottom $25 \%$ group would better capture the behavioural responses of the poor and (ii) they reflect local information, such as, differences of the food prices. It is also noted that any poverty line is used only as a reference point and the overall pattern of the simulation results will not change regardless of our choice of poverty cut-off point.

${ }^{6}$ While social, cultural, gender, educational and other dimensions conjointly determine the real access to goods and services and the achievement of a living standard (Sen, 1999), we use only the monetary measures of poverty because of the data constraints.
} 
they used international prices and assume full transmission into domestic markets. In addition to the question of using an appropriate deflator to convert prices into a comparable currency (Horton,1998), the degree and speed of transmission can differ between producers and consumers, among different regions within a country, and across countries. de Janvry and Sadoulet (2010) focus on the 2006-2008 crisis in Guatemala and exemplify this finding that poverty impacts are much lower than when full price transmission is assumed.

The impacts of price volatility are also uneven. For instance, a "one-time 10 percent increase in the price of rice may be comfortably absorbed by consumers in developed countries, but not so in many low-income countries" (Prakash 2010, p.5). Ulimwengu et al. (2009) found that losses in food consumption and nutrient intake are unevenly distributed geographically. Similarly, Chen and Ravallion (2004) find that absolute gains from price changes attributed to WTO accession are higher in richest provinces in China.

Focusing on differentiated impacts by household characteristics, FAO (2008a) estimated that the poorest, landless and female-headed households were hit harder. In Ethiopia households with lower levels of assets and those where the head of the household was a casual worker were more adversely affected in their general consumption and self-reported more distress and cuts in food consumption (Alem and Söderbom, 2010). Most studies consider both producer and consumers, whereas Dessus et al. (2008) calculate aggregate poverty changes considering solely urban households, assuming that food inflation affects only their consumption as their incomes are not greatly derived from food production activities. Finally, most of the studies incorporate only first round effects, but loses may be mitigated over the medium term by changes in consumption quantities (de Janvry and Sadoulet, 2010). Following de Janvry and Sadoulet, we will simulate both short-term (or first round) effects and medium term (or second round) effects. 


\section{Methodology}

As in most of the previous studies reviewed in the previous section, the cross-sectional structure of the ENIG data does not allow us to carry out before/after comparisons to derive a direct estimate of household welfare changes due to price surges over the years. Therefore, the study relies on simulations of potential scenarios following closely the methodological approaches used by Chen and Ravallion (2004), Ivanic and Martin (2008) and de Janvry and Sadoulet $(2008,2010) .{ }^{7}$ Our study goes beyond the first round effects by incorporating demand substitution responses in the medium term.

The underlying model can be described as follows. A household $(h)$ has a utility function $u_{h}\left(q_{h}^{F}, q_{h}^{N F}, L_{h}\right)$ that depends on a quantity of food and non-food demanded by the household $\left(q_{h}^{F}\right.$ and $q_{h}^{N F}$ ) and labor $L_{h}$ (Chen and Ravallion, 2004). Because we deal with urban households, we assume that all the household income are based on the verctor of wage rate and labour supplied (i.e., $y_{h}=w_{h} L_{h}$ ). All the household income is assumed to be consumed (no savings) and thus the budget constraint is written as $p_{h}^{F} q_{h}^{F}+p_{h}^{N F} q_{h}^{N F}=w_{h} L_{h}$ where $p_{h}^{F}$ (or $p_{h}^{N F}$ ) is the price vector for food consumption (or non food consumption) and $q_{h}^{F}$ (or $q_{h}^{N F}$ ) is a vector of food quantities (or non-food quantities) demanded by the househod, and $w_{h}$ is the vector of wage rates. The indirect utility function is specified as, follwing Chen and Ravallion (2004) but subsuming the profit term:

$$
V_{h}\left(p_{h}^{F}, p_{h}^{N F}, w_{h}\right)=\max _{q_{h}^{F}, q_{h}^{N F}, L_{h}}\left[u_{h}\left(q_{h}^{F}, q_{h}^{N F}, L_{h}\right) \mid p_{h}^{F} q_{h}^{F}+p_{h}^{N F} q_{h}^{N F}=w L_{h}\right]
$$

Taking the first derivatives of the indirect utility function:

\footnotetext{
${ }^{7}$ The present study presents a partial equilibrium analysis due to the data constraints. In contrast, a general equilibrium analysis would need to include the overall economy responses to the crisis as done by Chen and Ravaillion (2004) for China and by Thurlow et al. (2011) for Vietnam including the effect on employment and wages, transfers to households from remittances and government transfers and subsidies among others. de Janvry and Sadoulet $(2008$, p.12) argue, however, that 'partial equilibrium effects with behavioral responses will capture most of the large effects that we want to measure".
} 


$$
d V_{h}=\frac{d V_{h}}{d y_{h}}\left[p_{h}^{F} q_{h}^{F} d \ln p_{h}^{F}+p_{h}^{N F} q_{h}^{N F} d \ln p_{h}^{N F}+w_{h} L_{h} d \ln w_{h}\right]
$$

The welfare change (in monetary terms) of any price increase is given as a simplified version (where the household production is subsumed) of de Janvry and Sadoulet's (2008, p.8) equation (3):

$$
d W_{h}=-p_{h}^{F} q_{h}^{F} d \ln p_{h}^{F}-p_{h}^{N F} q_{h}^{N F} d \ln p_{h}^{N F}+w L_{h} d \ln w_{h}
$$

As this is a partial equilibrium analysis, other prices in the economy remain constant while only food prices fluctuate (that is, $d \ln p_{h}^{N F}$ and $d \ln w_{h}$ are both zero). Considering also that $d \ln p_{h}^{F} \approx d p_{h}^{F} / p_{h}^{F}$ and disaggregating among different food items ( $g$ ) (de Janvry \& Sadoulet, 2010):

$$
d W_{h}=\sum_{g}\left(-\operatorname{Exp}_{g h}^{F} \frac{d p_{g}^{F}}{p_{g}^{F}}\right)
$$

where $E x p_{g h}^{F}=q_{g}^{F} p_{g}^{F}$ is the monetary expenditure of each household on good $g . d W_{h}$ is the compensated variation or the monetary amount that households should be given to maintain the same utility level as before (de Janvry and Sadoulet, 2008). It represents the expected loss in consumption caused by the food price increase. Though it is obvious that the monetary expenditure represents only a part of household welfare, 'household welfare' is proxied by 'household (monetary) expenditure' in the present study due to the data constraints, such as lack of non-monetary measures of welfare in our data (e.g. qualitative measures of happiness or life satisfaction or health conditions of household members). Expenditure is a more appropriate welfare measure than income when estimating the effects of price changes (Leyaro et al., 2010) as earnings may not translate into actual consumption of goods and services from which individuals derive utility and are more prone to seasonal patterns of fluctuations and volatility (Deaton, 1997).

To address the household specific short-term welfare impacts using the equation (4) we calculate the 'new achievable level of expenditure' for each household, adding initial 
expenditure and the compensated variation (Ivanic and Martin, 2008). The achievable level of expenditure of a household is defined as the sum of current monetary and non-monetary expenditures. Non-monetary expenditures included are: estimation of the economic benefit of home ownership, in kind benefits, expenditure that would have to be made when the children receive food at school. Self-consumption is not included because it is not reported in the ENIG. Non-discretionary expenditures, such as taxes and social security contributions are also excluded. This imputations are made following ECLAC (2005) recommendations and the methodological document of the ENIG (DANE, 2009).

The poverty line needs to be updated to account for change in the cost of the consumption basket (de Janvry and Sadoulet, 2008). To do this, the additional expenditure that would be needed to maintain the marginally poor at the same level of utility is obtained by multiplying food expenditures by the change in their prices. Aggregate food price and total food expenditure are used, and the marginally poor are those within a 5\% upward and downward boundary of the poverty threshold (ibid., 2008).

Where $\mathrm{z}$ is the EPL, $d z_{h}$ represents the change in the cost of food consumption caused by the price increase:

$$
d z_{h}=\operatorname{Exp}_{h}^{F} \frac{d p_{h}^{F}}{p_{h}^{F}}
$$

$\operatorname{Exp}_{h}^{F}$ is per capita expenditure of the household on food and $\frac{d p_{h}^{F}}{p_{h}^{F}}$ is the proportional change in food prices faced by the household $h$. The adjustment of the EPL, $\bar{z}$, is the average $d z_{h}$ for the marginally poor. The MPL is adjusted by the same amount.

$$
z_{1}=z_{0}+d \bar{z}
$$

The third step is to address the medium term impacts by allowing for demand responses to the food price increase. 
Janvry and Sadoulet (2010) consider the medium-term welfare effect of food price changes by simulating demand and supply responses where the food price surges are allowed to increase supplies or decrease demands, but they did not take into account cross-price elasticities, that is, they assumed that the price of a particular commodity affects only its own supply or demand. Because we focus on only urban households, we incorporate only demand responses in the medium term. Following the methodology in de Janvry and Sadoulet (2008, 2010), the medium term welfare change can be written as:

$$
d W_{h}=-\sum_{g}\left[\operatorname{Exp} p_{h}^{F}\left\{1+\left(\frac{1}{2} \varepsilon_{g h} \frac{d p_{g}^{F}}{p_{g}^{F}}\right)\right\} \frac{d p_{g}^{F}}{p_{g}^{F}}\right]
$$

Consequently, and because detailed price data was available for each city, the procedure takes a standard Working-Leser model as explained in Chern et al. (2003). For each item and each expenditure quintile, a consumption equation is defined in terms of budget shares. Because not all households consume all commodities, it does not take a logarithmic specification which would only work for households with positive consumption.

$$
s_{g h}=\alpha_{g}+\beta_{g} \ln \left(T E x p_{h}\right)+\gamma_{g} x_{h}+\theta_{g} \ln p_{g}^{F}+\theta_{G} \ln p_{G}^{F}+u_{g h}
$$

$s_{g h}$ is the household budget share for a particular food item g (e.g. potatoes), TExp is household's total expenditure and $x_{h}$ a vector of household characteristics (e.g. family size, dependency ratio, head of household sex and educational level). To control for increases in other prices, we include $p_{g}^{F}$, the price of a particular item and $p_{G}^{F}$, the overall food price. $u_{g h}$ is an error term, independent and identically distributed. The equation (8) is estimated for each food item.

Price elasticities are (Chern et al., 2003):

$$
\varepsilon_{g j}=\left(\theta_{g j} / s_{g}\right)-\delta_{g j}
$$


$\delta_{g j}$ is the Kroneker delta ${ }^{8}$ and as cross-price elasticities are not considered $\delta_{g j}=1$.

Results of absolute and proportional losses - to initial expenditure per capita - will be presented. They will be disaggregated by city, initial expenditure level and household characteristics to assess whether there are concentrations of losers and enable the analysis of potential distributional impacts of the price surge.

\section{Results}

The overall average baseline extreme poverty headcount was $6.26 \%$ and moderate poverty $35.04 \%$. These figures are slightly higher than the trend shown in official poverty figures in Colombia $^{9}$ which are calculated using incomes instead of expenditures. Across cities, extreme poverty ranges from $2.96 \%$ in Bogota to $17.04 \%$ in Barranquilla. Moderate poverty was the lowest in Pasto (25.26\%) and the highest in Manizales (57.81\%). Cities with higher extreme poverty are also the ones with higher moderate poverty although not exactly in the same order.

When using a uniform 30\% price increase (column (a) of Table 1) the MPL goes up by an average of COP $\$ 13,820$. In contrast when using the actual food price change for the 20062008 period (column (b)), the increase is slightly lower (COP\$13,339) except in cities for which overall food inflation was over 30\% (Barranquilla, Neiva and Cucuta) (Table 1). For the remainder results obtained using the actual price change will be highlighted as they better reflect the conditions in each city allowing a closer picture of the real impacts.

[Table 1 to be inserted around here]

\footnotetext{
${ }^{8} \delta_{g j}=\left\{\begin{array}{l}1 \text { if } g=j \\ 0 \text { if } g \neq j\end{array}\right.$

${ }^{9}$ Due to the methodological change, no official poverty measure is available for 2007 . We thus compare the results with those of 2005 and 2008.
} 
Because poverty lines are highly elastic to relative food prices (Bresciani and Valdes, 2007), changes in them result in variations of poverty prevalence. This is consistent with the findings, given that adjusting the lines already increases extreme poverty headcount by $1.8 \%$ and moderate by $2.37 \%$ on average for the 13 cities. The greater increase is observed in extreme poverty as expected, because households closer to the EPL are the ones with larger food budget shares and thus more negatively affected by the rise in the cost of the basic consumption basket. However, this result is not consistent across cities and, for seven of the thirteen, extreme poverty varies less than moderate poverty (in percentage terms).

Table 2 reports the results for poverty head count ratios for each city. ${ }^{10}$ The first column 'Baseline' shows the actual poverty head counts, while the column titled 'EPL adjustment' or 'MPL adjustment' reports the poverty headcount ratios where the poverty thresholds are adjusted to reflect the change of the cost of the consumption basket due to the price surges in 2006-2008 (de Janvry and Sadoulet, 2008). The following two columns show the poverty headcounts after the households' welfare changes are accounted. Due to the food price surge, the households which were under the extreme poverty line on average increased from $6.26 \%$ to $9.75 \%$ in the short term where only (actual) price changes are taken into account, and to $9.15 \%$ in the middle term where demand response is incorporated. Those under the moderate poverty line will increase from $35.0 \%$ to $39.2 \%$ in the short run and to $38.3 \%$ in the middle run. The poverty headcount ratios will marginally increase in both short and middle run from the cases where the poverty lines are adjusted for the food price surges. While poverty headcount ratios in all the cities rise due to the price surges, the extent they are affected differs among different cities, though any generalization would be difficult. For example, because of the price surges, Medellin would experience only small increase in both extreme

\footnotetext{
${ }^{10}$ The results for poverty gap show the similar pattern and will be provided from the author on request.
} 
and moderate poverty in the short and middle run, while the cities like, Barranquilla, Monteria and Nevia would see a relatively large poverty increase in extreme poverty.

\section{[Table 2 to be inserted around here]}

Tables A.1 and A.2 in Appendix summarize the results of consumption equation regressions used to estimate price elasticities based on the equation (8). As explained in the previous section, the budget share of each food item is regressed on its own price controlling for total household expenditure, other household characteristics and overall food price level. The CPI coefficient represents the proportional change in the share of the budget of a specific food item when its price changes.

Elasticities were estimated for each quintile using CPI in levels and its monthly and annual variation as shown in Table A.3 in Appendix ${ }^{11}$. As expected, basic staples are inelastic for most quintiles; this is the case for rice, potatoes, legumes, eggs and milk. Bread, pork, fish, oils and panela were found to be elastic goods. Beef ${ }^{12}$, milk and oils showed a pattern of being relatively inelastic for the lowest expenditure quintiles and more elastic for the highest ones, while sugar and panela have an opposite pattern.

Based on these estimates of price elasticies, the welfare changes in the short and middle run can be derived at household levels using the equations (4) and (7). Household level estimates are then aggregated for each city. The results of short and middle term welfare changes are reported in the last two columns of Table 2. The average welfare reduction for

\footnotetext{
${ }^{11}$ When using price variations, whether monthly or accumulated, the elasticities are almost always unity. Due to this lack of variability, only the first set (CPI level) of elasticities are used in the final estimation. In addition, these are consistent with the estimations of Cortés and Pérez (2010) who find a food elasticity of -1.407 . For the 13 items and averaging across quintiles our estimation is 1.101. This is expected considering the fact that basic commodities tend to be more inelastic.

${ }^{12}$ Although beef is relatively expensive, it was inelastic for the lowest quintiles. This was possibly because its consumption is already low for these groups it is not easy to further reduce it even when they faced with a price increase.
} 
the whole sample is COP $\$ 16666.3$, but when consumption responses are allowed this is almost halved.

Absolute change in the capital is the largest, but this is also the city with the highest initial expenditure level highlighting the importance of consider proportional changes as well. The magnitude of the welfare change is larger for the cities classified as those with middle cost of living (Romero, 2007) ${ }^{13}$ (Figure 2) which relates to the fact that these four were among the ones with largest price increases.

\section{[Figure 2 to be inserted around here]}

The relationship between absolute and relative welfare changes and initial expenditures is not completely clear, perhaps because the distribution of initial expenditure is highly concentrated in the lower bound. Nonetheless, when looking at the average proportional changes by quintile (Figures 3 and 4), the lowest quintiles are clearly the worst hit, while the average household in the first quintile loses $4.5 \%$ of their welfare and the one in the highest quintile loses only $0.73 \%$.

\section{[Figures 3 and 4 to be inserted around here]}

By dependency rate, the result is similar; loses of households with lower dependency rates are smaller in proportion to their incomes but, as the dependency rate increases the relationship loses strength. This is in line with Alem and Söderbom (2010) finding of the absence of significance of demographic characteristics. However, in contrast to the results for Ethiopia, in Colombia the educational level seems to be an important determinant of the

\footnotetext{
${ }^{13}$ High living costs cities are Cartagena, Medellin, Cali, Bogota and Barranquilla, the five biggest cities in the country. Cities with intermediate living cost are Manizales, Pasto, Pereira and Cucuta. Low cost cities are Bucaramanga, Neiva, Villavicencio and Monteria.
} 
severity of the outcomes as those households for which the head of the household had higher educational attainment level are less affected (Table 3).

\section{[Table 3 to be inserted around here]}

An interesting result is that households that (subjectively) perceive that their incomes are not enough to cover the basic expenditures loose more than twice of their proportional expenditure than those who believe their incomes are enough. Female headed households are also more negatively affected in absolute and relative terms, but the average difference of the welfare impact in female headed against male headed households (COP\$ 722.4) is not as large as those found by initial expenditure or educational level.

The relationship between the initial share of food expenditure in total household expenditure and the proportional welfare changes is shown in Figure 5. It is observed that the variance of proportional welfare changes is larger for households with higher levels of food expenditure share. This means that for households with higher food budget shares, the proportional losses could be large or small, while for households with lower food shares the losses are usually not so large.

\section{[Figure 5 to be inserted around here]}

We have compared the aggregate poverty levels for each city before and after the food price surges. ${ }^{14}$ A city that seems to be highly affected by the food price surge is Barranquilla; it was among the top in both extreme and moderate poverty increases in the short and medium terms. Here extreme poverty rises by $9.05 \%$ and $7.39 \%$ in the short and medium term respectively, which is more than double the average (3.48\% and $2.88 \%)$. Moreover, this is the city where general poverty increases the most, although is not the one with the largest

\footnotetext{
${ }^{14}$ A full set of results will be available on request.
} 
initial level. Another concerning city case is Monteria where extreme poverty increases substantially, reaching $24.93 \%$ over the medium term. In contrast the rise in moderate poverty is not as large, although it is above the Colombian average. The two cities with the highest initial poverty, Monteria and Manizales, were not necessarily those with the biggest increases. Additionally, Bogota, which had the lowest initial poverty headcount, had poverty increases above the average.

Finally, it is important to see how the effect in poverty is reversed slightly when demand responses are allowed. Quantities consumed decrease as households try to smooth consumption, slightly reducing expenditure. These second order effects are often small compared to the initial households' responses (de Janvry and Sadoulet, 2008). Figures 6.1 6.4 show a visual representation of what would be the evolution of the poverty indicators across cities.

\section{[Figures 6.1 -6.4 to be inserted around here]}

According to the poverty gap calculations, the extent to which individuals in the 13 Colombian cities fall below extreme poverty was on average $1.5 \%$ and $4.2 \%$ in the moderate case. Barranquilla was again the city where the extreme poverty gap was highest and also the one where its increase was the largest in all three simulation steps. On the contrary, Bogota was the one with the lowest score $(0.5 \%)$ and remained in this position after the price increases took place $(0.94 \%$ over the medium term $)$.

If we consider the poverty gap as the measure of the fiscal cost of eliminating poverty, Monteria, Barranquilla and Manizales where the three cases where the price increase could be more costly to address. As with the extreme poverty gap, the moderate poverty gap remained highly concentrated in some cities after the food price surge, ranging from $2.65 \%$ in Bogota to $14.88 \%$ in Barranquilla. 


\section{Policy Discussions}

Assessing disaggregated impacts of the food price surge is important for policy purposes. This view is shared throughout the literature; for example Ulimwengu et al. (2009, p.15) argue that "effective policy responses should account for geographic heterogeneity in household consumption behavior ... targeting national averages might not be efficient". The responses implemented by countries worldwide during and after the food price crisis can be divided into three broad categories: producer oriented, consumer oriented or trade oriented (Coloumbe and Wodon, 2008; Demeke et al., 2011; FAO, 2008b). Despite some variation, the general pattern was a change of policy emphasis as many developing countries have moved towards an attempt to isolate the domestic agricultural commodity market from the world market to protect domestic producers (e.g. Demeke et al., 2011). However, de Janvry and Sadoulet (2010, p.1336) argue that "(w)hen the price shock originates in the international market, limited price transmission is an advantage. Had the price shock originated in domestic production, greater integration into the international market would have been an advantage. Hence, food security must not go the way of autarky, but of using trade policies to mitigate the transmission of acute price spikes to shelter the welfare of the poor".

Colombia has followed the attempt to rely less on food imports and used mostly producer oriented strategies. For instance, in December 2007, the government, the biggest supply centers and food retail chains agreed to freeze food prices for almost two months without much success. In February 2008, the Treasury proposed a new agreement, but it was not backed up by trade unions and think tanks which believed it did not addressed the root causes of inflation (Dominguez, 2008).

Nonetheless, macro strategies need to be complemented with household oriented policies given the heterogeneity of the impacts of price surges on different cities or different 
households as shown by the present study. Releasing stocks and providing consumption subsidies were common demand oriented responses in many countries (Demeke et al., 2011), but in Colombia, the reaction to the crisis was mainly directed to control prices and increase supply, and not much on food programs and social safety nets.

These programs are not inexistent. On the contrary, conditional cash transfer and nutritional programs have been implemented at both the national and municipal levels. A renowned one is "Bogotá sin hambre" (Bogota without hunger) and, although it has expanded and spread out to other municipalities in the past years, this was not necessarily a deliberate effort to respond to the price crisis as was the case in other Latin American countries such as Brazil, Ecuador and Mexico (Demeke et al., 2011). The strategy of raising the transfer and expanding coverage of existing programs could be extremely important because constraints at the micro level help to explain the partial achievements of macro level policies to promote food security (Rapsomanikis, 2009).

In fact, although these conditional cash and in kind transfer programs have been found to be effective and authors, such as Tiba (2011) who regards them as the best option, it takes time for these programs to be in operation and this was a barrier to comprise a rapid response in the 2008 crisis (Demeke et al., 2011). On the other hand, universal subsidies or transfers, although quicker and easier to launch, are costly and do not necessarily reach those who need more support (Rapsomanikis, 2009).

Three methods of targeting have been proposed - by individual eligibility, by category or by self-selection (Tiba, 2011). The methodology and results presented here could be used to target either by selecting beneficiaries by category (demographic targeting) or by location (geographical targeting). This may be particularly helpful when time, information and resource restrictions are present and the problem is particularly acute in a specific city or a demographic group. Coulombe and Wodon (2008) support geographical targeting methods 
and advocate for the use of poverty maps to do so. This would be possible with the same methodology and adding geographical referencing data to construct inter-city extensions of this study to set up poverty maps. Our results suggest that the cities with higher initial poverty rates (e.g. Barranquilla) are likely to be vulnerable and should be targeted. In addition, the households in the lower quintiles, with less educational level and female headed households should be protected as they are more likely to be vulnerable to price shocks. However, these targeting policies are not, of course, free of selection biases and should be combined with other alternatives.

A second possible application of the results is to facilitate the determination of the level of benefit when the program consists of a cash transfer. This is a difficult task as "(a) benefit set too high will cause fiscal burden and may generate dependency, reduce work incentives and crowd out private transfers. If, on the other hand, the benefit is too low, the program will lack impact and fail to achieve its objectives, while incurring high administrative costs relative to the size of the transfer" (Tiba, 2011, p.500). If the purpose is to lift beneficiaries' achievable expenditure up to the point where they were before the price shock, the measure of the welfare change $\left(d W_{h}\right)$ could be used. If the intention goes further on, the adjusted poverty line or new poverty gap could be used to compute the appropriate cash transfer needed for a household to be able to buy the minimum food basket. For example, according to the results for the adjusted MPL, a program in Bogota would need to lift achievable monetary consumption to COP\$ 122,776 and in Cartagena that value would be COP\$ 135,702. Also the disaggregated results could be used to set a variable benefit among different types of households.

It should be noticed that these strategies may work only in the short and middle term. They serve the role of insurance mechanisms "in an environment of rapidly increasing food prices, the provision of subsidized food or cash to poor through safety nets improves their 
ability to cope with increased expenditure and prevents households from divesting in assets that are important for their well-being" (Rapsomanikis, 2009, p. 57).

In the long run, household assets, livelihood options and social security nets may be more important than transfers. These could be helpful to 'protect entitlements' but complimentary policies would be needed to 'promote entitlements' (Maxwell and Smith, 1992). Nevertheless, although the first purpose of these programs is to avoid starvation and malnutrition, they have the potential to achieve parallel objectives and they are now often designed to do so. For instance, a program providing free school meals can not only sustain nutritional intake of children but also avoid parents taking children out of school because of economic distress.

Finally, the analysis addresses only national and sub national policy responses. However, the international agricultural and price-setting context could also have important implications that are not referred to here. Specific implications of international negotiations on agricultural trade are also important for countries to consider when addressing food price volatility and its effects.

\section{Concluding remarks}

From the end of 2006 to 2008 the price of food stepped up. The present study was an attempt to measure the impacts of this on the welfare of consumer households and on aggregate poverty in the main Colombian cities. According to our estimations, the average welfare loss was COP\$16,666.3 over the short term and COP\$8,479.6 in the medium term as households adjust consumed quantities. Extreme poverty increased almost three percentage points and moderate poverty $3.3 \%$ to reach a level of $38.33 \%$. The average value to which poor households fell below the poverty threshold also showed an increase of $1.9 \%$ across the 13 cities. 
These results were not homogeneous geographically or by household type. Although the higher increases were not found in the poorest cities, there was a high correlation between the initial and final poverty levels, implying persistence in aggregate poverty. In addition, the findings suggest that the urban poorest and less educated households were the most affected. Lower quintile population, who spend larger shares of their budgets on food, suffered larger proportional welfare loses. Consistent with this, for most of the cities extreme poverty escalated the most. The fact that the largest impacts are more acute in specific groups and cities could be used to better direct efforts to adopt policies aimed at mitigating the adverse effects of the price surge and protect households' welfare, especially considering the restrictions in time, information and resources. The findings are important given the likely reoccurrence of this type of price episode. Food prices have continued to rise and be volatile in more recent years (World Bank, 2011; FAO, 2011b) and climate change and erratic climate patterns along with economic crisis and price volatility will aggravate hunger problems around the world (FAO, 2011b) and Colombia will be no exception.

Additionally, although the study only focuses on urban households, it is plausible that rural ones may also be negatively affected; this has also been found in previous empirical studies in clear opposition to theoretical predictions (de Janvry and Sadoulet, 2010; Ivanic and Martin, 2008). In fact, in 2008, towards the end of the crisis there was a growth in world wheat production but it mainly involved developed countries, implying that net producer households in the poorest countries would not necessarily benefit from higher prices (FAO, 2008b). Studies are required to estimate the effects of food price changes on households in both rural and urban areas of Colombia.

Finally, this study was an attempt to link macroeconomic events with their microeconomic consequences. It was shown how price movements felt at the global level had particular manifestations at the national level and were in turn transmitted to households. A 
further line of research would be to explore the issue of poverty dynamics using both monetary and non-monetary measures with a focus on the long-term livelihood strategies of poor households facing price shocks.

\section{References}

Alem, Y. and Söderbom, M., 2010. Household-Level Consumption in Urban Ethiopia: The Impact of Food Price Inflation and Idiosyncratic Shocks, CSAE Working Paper Series, 24.

Alvarez, M.C., Estrada, A., Montoya, E.C. and Melgar, H., 2006. Validación de escala de la seguridad alimentaria doméstica en Antioquia, Colombia (Validation of the domestic food security scale in Antioquia, Colombia). Salud Pública de México. 48(6), 474-481.

Banerjee, A. and Duflo, E., 2011. Poor Economics: A Radical Rethinking of the Way to Fight Global Poverty. Public Affairs, New York.

BanRep., 2007. Report on inflation March/December 2007. Central Bank Colombia, Bogota.

BanRep, 2008. Report on inflation December 2008, Central Bank of Colombia, Bogota.

Brandt, H. and Otzen, U., 2007. Poverty Orientated Agricultural and Rural Development. Routledge, UK, London.

Bresciani, F. and Valdes, A., 2007. The role of agriculture in poverty reduction: a synthesis of the country case studies, in Bresciani, F. and Valdes, A. eds., Beyond food production. The role of agriculture in poverty reduction. FAO; Edward Elgar Publishing, Cheltenham \& Northampton, MA, pp. 3-40.

Chen, S. and Ravallion, M., 2004. Welfare Impacts of China's Accession to the World Trade Organization. World Bank Econ. Rev. 18, 29-57.

Chern, W. S., Ishibashi, K., Taniguchi, K. and Tokoyama, Y., 2003. Econometric models for consumption analysis. In Analysis of the Food Consumption of Japanese Households. 
FAO Economic and social development paper, FAO, Rome. Accessed December 2011, available at: http://www.fao.org/DOCREP/005/Y4475E/y4475e07.htm.

Cortés, D. and Pérez, J.E., 2010. Colombian household consumption, 2006-2007: Demand systems estimation (El consumo de los hogares colombianos, 2006-2007: estimación de sistemas de demanda). Desarrollo y Sociedad, 66, 7-44.

Coulombe, H. and Wodon, Q.. 2008. Assessing the geographic impact of higher food prices in Guinea. World Bank Policy Research Working Paper 4743. World Bank, Washington D.C.

DANE, 2009. Methodology of the ENIG 2006-2007 (Metodologia de la encuesta de ingresos y gastos 2006-2007). National Statistics Department (Departamento Nacional de Estadística), Bogota.

DANE, 2011. Consumer price index. Base 2008 (National Statistics Department). Accessed December 2011, available at:

http://www.dane.gov.co/daneweb_V09/index.php?option=com_content\&view=article\&i $\underline{\mathrm{d}=103 \& \text { Itemid }=76}$.

Deaton, A., 1997. The analysis of household surveys. World Bank; The Jhon Hopkins University Press, Washington, D.C; Baltimore; Maryland.

de Janvry, A. and Sadoulet, E., 2008. Methodological note: Estimating the effects of the food price surge on the welfare of the poor. Prepared for the UNDP/RBLAC, Poverty and MDG Cluster project: Food Security and Commodity Prices:Consequences and Challenges for Latin America. Accessed December 2011, available at: http://are.berkeley.edu/ sadoulet/papers/FoodPriceMethodologyDec08.pdf. de Janvry, A. and Sadoulet, E., 2010. The Global Food Crisis and Guatemala: What Crisis and for Whom? World Dev. 38(9), 1328-1339. 
Demeke, M., Panagrazio, G. and Maetz, M., 2011. Country responses to turmoil in global food markets: the nature and preliminary implications of the policies pursued in the 2006-08 episode, in Prakash, A. ed., Safeguarding food security in volatile global markets. Rome: Food and Agriculture Organization of the United Nations. pp. 185-212.

Dessus, S., Herrera, S. and de Hoyos, R., 2008. The impact of food inflation on urban poverty and its monetary cost: some back-of-the-envelope calculations. Agric. Econ. 39(s1), 417-429.

DNP, 2011. MESEP / Misión para el Empalme de las Series de Empleo, Pobreza y Desigualdad. Accessed December 2011, available at http://www.dnp.gov.co/LinkClick.aspx?fileticket=DXInD1TENeU\%3D\&tabid=337.

Dominguez, J.C., 2008. Treasury's food price control propositon was rejected by trade unions and experts (Propuesta de Minhacienda de controlar precios de alimentos fue rechazada por gremios y expertos). El Tiempo.com, February 5. Accessed December 2011, available at http://www.eltiempo.com/archivo/documento/CMS-3947030.

ECLAC, 2005. Extreme poverty measurement according to the "1 dolar-a-day" and the national lines (Medicion de la pobreza extrema segun la linea de "1 dolar al dia" y las lineas nacionales, in UN, Mileniumm Development Goals: A look from Latina America and the Caribbean (Objetivos de desarrollo del milenio: una mirada desde américa latina y el caribe). United Nations, Santiago, pp. 33-35.

FAO, 2008a. High food prices and food security. Poor households worst hit, in The state of food insecurity in the world 2008. High food prices and food security threats and opportunities. FAO, Rome, pp. 22-31.

FAO, 2008b. Crop Prospects and Food Situation (5). Accessed December 2011, available at ftp://ftp.fao.org/docrep/fao/011/ai476e/ai476e00.pdf. 
FAO, 2010. Colombia Country Profile: Food Security Indicators. Accessed December 2011, available at: http://www.fao.org/fileadmin/templates/ess/documents/food_security_statistics/country_ profiles/eng/Colombia_E.pdf.

FAO, 2011a. Food Outlook: Global Market Analysis: June 2011. FAO, Rome. Accessed December 2011, available at http://www.fao.org/docrep/014/al978e/al978e00.pdf.

FAO, 2011b. The State of Food Insecurity in the World: How does international price volatility affect domestic economies and food security? FAO, Rome.

High Commissioner for Human Rights and FAO, 2010. The Right to Adequate Food. Fact Sheet, no. 34. Accessed December 2011, available at http://www.ohchr.org/Documents/Publications/FactSheet34en.pdf.

Horton, S., 1988. The social costs of higher food prices: Some cross-country evidence. World Dev. 16(7), 847-856.

ICBF, 2005. National nutritional situation survey in Colombia 2005 (Encuesta nacional de la situación nutricional en Colombia 2005). Colombian Insititute of Family Wellbeing (Instituto Colombiano de Bienestar Familiar), Bogota.

Ivanic, M. and Martin, W., 2008.. Implications of higher global food prices for poverty in low-income countries. Agric. Econ. 39(s1), 405-416.

Leyaro, V., Morrisey, O., Owens, T., 2010. Food prices, tax reforms and consumer welfare in Tanzania 1991-2007. Int. Tax Public Finan. 17, 430-450.

Maxwell, S. and Smith, M., 1992. Household food security: a conceptual review, in Maxwell, S. and Frankenberger, T. eds., Household Food Security: concepts, indicators, measurements. A technical review. IFAD; UNICEF, Rome; New York.

Muñoz, M. and Rivas, G., 2006. Normative food basket construction for thirteen cities, urban remaining and rural area (Construcción de las canastas normativas de alimentos 
para trece ciudades, resto urbano y zona rural). National Planning Department (Departamento Nacional de Planeacion), Bogota.

Oxfam, 2011. Preparing for thin cows why the G20 should keep buffer stocks on the agenda. Oxfam briefing note. Accessed December 2011, available at http://www.oxfam.org/en/grow/policy/preparing-for-thin-cows.

Prakash, A., 2010. Why volatility matters, in Prakash, A. ed., Price Volatility in Agricultural Markets. FAO, Rome, pp. 3-28.

Rapsomanikis, G., 2009. The 2007-2008 Food Price Swing: Impact and Policies in Eastern and Southern Africa. Commodities and Trade Technical Paper. FAO, Rome.

Ravallion, M., 1998. Poverty lines in theory and practice, LSMS working paper 133. World Bank, Washington D.C.

Reddy, S., 2004. A capability-based approach to estimating global poverty. In focus. International poverty centre, (4), pp. 6-8. Accessed December 2011, available at http://www.ipc-undp.org/pub/IPCPovertyInFocus4.pdf.

Romero, J., 2007. Inflation and cost of living in the main Colombian cities (Inflación y costo de vida en las principales ciudades colombianas), Regional Economy working paper, 99. Banco de la Republica, Cartagena.

Sen, A., 1980. Famines. World Dev. 8(9), 613-621.

Sen, A., 1999. Development as freedom. Oxford University press, Oxford.

Sheeran, J., 2011. Ending hunger now, TED talks. Accessed December 2011, available at: http://www.ted.com/talks/josette_sheeran_ending_hunger_now.html?utm_source=feedb urner.

Srinivasan, T. N., 2001. Comment on "Counting the World's Poor" by Angus Deaton. World Bank Res. Obser. 16(2), 157-168. 
Tiba, Z., 2011. Targetting the most vulnerable: implementing social safety nets, in Prakash, A., ed., Safeguarding food security in volatile global markets. FAO, Rome, p. 493.

Thurlow, J., Tarp, F. McCoy, S., Hai, Nguyen, M., Breisinger, C., and Arndt, C., 2011. The impact of the global commodity and financial crises on poverty in Vietnam. $J$. Globalization and Dev. 2(1), 1-29.

Ulimwengu, J., Workneh, S. and Paulos, Z., 2009. Impact of Soaring Food Price in Ethiopia. Does location matter? IFPRI discussion papers 846. IFPRI, Washington D.C.

UNDP, 2004. Dollar a day. How much does it say? In focus (4). Accessed December 2011, Available at: http://www.ipc-undp.org/pub/IPCPovertyInFocus4.pdf.

World Bank, 2011. Food Price Watch: August 2011. Accessed December 2011, available at http://siteresources.worldbank.org/INTPOVERTY/News and Events/22982477/FoodPrice-Watch-August-2011.htm?cid=AFR_FBWorldBankAfrica_P_EXT. 
Table 1

New poverty lines

(Unit: COP\$)

\begin{tabular}{|c|c|c|c|c|}
\hline \multirow[b]{2}{*}{ City } & \multicolumn{2}{|c|}{$\begin{array}{c}\text { EPL } \\
\text { (Extreme Poverty Line) }\end{array}$} & \multicolumn{2}{|c|}{$\begin{array}{c}\text { MPL } \\
\text { (Moderate Poverty Line) }\end{array}$} \\
\hline & (a) & (b) & (a) & (b) \\
\hline Medellin & 132933 & 132154 & 323054 & 322275 \\
\hline Barranquilla & 137993 & 139763 & 257893 & 259663 \\
\hline Bogota & 123444 & 122776 & 284498 & 283831 \\
\hline Cartagena & 138775 & 135702 & 246955 & 243881 \\
\hline Manizales & 143016 & 142228 & 387516 & 386727 \\
\hline Monteria & 129938 & 128440 & 272511 & 271013 \\
\hline Neiva & 137560 & 139965 & 309343 & 311749 \\
\hline Villavicencio & 124541 & 123727 & 274270 & 273456 \\
\hline Pasto & 91676.7 & 89363.2 & 205268 & 202954 \\
\hline Cucuta & 112726 & 113315 & 243679 & 244269 \\
\hline Pereira & 137780 & 137663 & 336363 & 336247 \\
\hline Bucaramanga & 122716 & 122474 & 290450 & 290208 \\
\hline Cali & 132845 & 130433 & 302598 & 300186 \\
\hline
\end{tabular}

Source: Authors' calculations based on ENIG data

Note: Case (a) assumes a uniform 30\% price increase, while Case (b) uses the actual food price change for the 2006-2008 period. 
Table 2

Short-term and middle-term effects of food price surges on poverty headcount ratios

\begin{tabular}{|c|c|c|c|c|c|c|c|c|c|c|}
\hline \multirow[b]{2}{*}{ City } & \multicolumn{4}{|c|}{$\begin{array}{c}\text { Extreme poverty } \\
(\%)\end{array}$} & \multicolumn{4}{|c|}{$\begin{array}{c}\text { Moderate poverty } \\
(\%)\end{array}$} & \multicolumn{2}{|c|}{$\begin{array}{c}\text { Welfare Changes } \\
\text { (COP\$) }\end{array}$} \\
\hline & Baseline & $\begin{array}{c}\mathrm{EPL} \\
\text { adjustment }\end{array}$ & $\begin{array}{l}\text { Short } \\
\text { term }\end{array}$ & $\begin{array}{c}\text { Middle } \\
\text { term }\end{array}$ & Baseline & $\begin{array}{c}\text { MPL } \\
\text { adjustment }\end{array}$ & $\begin{array}{l}\text { Short } \\
\text { term }\end{array}$ & $\begin{array}{l}\text { Middle } \\
\text { term }\end{array}$ & $\begin{array}{l}\text { Short } \\
\text { term }\end{array}$ & $\begin{array}{c}\text { Medium } \\
\text { term }\end{array}$ \\
\hline Medellin & 9.46 & 11.17 & 12.39 & 11.91 & 44.74 & 45.76 & 46.34 & 45.86 & -10975 & -5403 \\
\hline Barranquilla & 17.04 & 21.82 & 26.09 & 24.43 & 49.09 & 52.15 & 55.26 & 53.73 & -17984 & -9266 \\
\hline Bogota & 2.69 & 3.465 & 4.525 & 4.284 & 25.57 & 28.22 & 29.87 & 29.12 & -20580 & -10334 \\
\hline Cartagena & 16.64 & 20.11 & 23.31 & 21.9 & 48.71 & 50.85 & 53.01 & 51.87 & -11018 & -5782 \\
\hline Manizales & 13.17 & 17.4 & 20.37 & 19.47 & 57.81 & 59.62 & 62.54 & 61.37 & -17839 & -9256 \\
\hline Monteria & 17.01 & 22.36 & 26.49 & 24.93 & 59.09 & 61.2 & 63.9 & 62.8 & -15181 & -8060 \\
\hline Neiva & 10.73 & 15.22 & 18.17 & 17.09 & 48.84 & 51.69 & 53.35 & 52.85 & -14037 & -7497 \\
\hline Villavicencio & 4.665 & 6.014 & 8.191 & 7.161 & 31.73 & 34.23 & 37.47 & 35.98 & -16020 & -8286 \\
\hline Pasto & 3.261 & 4.588 & 5.592 & 5.156 & 25.26 & 27.45 & 30.23 & 28.59 & -19838 & -10240 \\
\hline Cucuta & 5.492 & 7.527 & 10.6 & 9.093 & 37.7 & 39.85 & 42.15 & 40.54 & -13297 & -6662 \\
\hline Pereira & 9.744 & 13.23 & 15.54 & 14.78 & 54.82 & 57.39 & 58.63 & 57.82 & -16897 & -8886 \\
\hline Bucaramanga & 2.4 & 4.402 & 6.156 & 5.217 & 33.05 & 35.71 & 38.01 & 37.01 & -14694 & -7108 \\
\hline Cali & 4.267 & 6.012 & 7.574 & 7.065 & 34.6 & 37.25 & 39.53 & 38.37 & -12261 & -6696 \\
\hline Total & 6.26 & 8.04 & 9.75 & 9.15 & 35 & 37.4 & 39.2 & 38.3 & -16666 & -8480 \\
\hline
\end{tabular}

Source: Authors' calculations based on ENIG data. 
Table 3

Welfare change by educational level

\begin{tabular}{|c|c|c|}
\hline & $\begin{array}{l}\text { Absolute } \\
\text { (COP\$) }\end{array}$ & $\begin{array}{l}\text { Proportional } \\
\text { (\%) }\end{array}$ \\
\hline Incomplete Primary & -5143.3 & -8.38 \\
\hline Primary & -8100.3 & -2.96 \\
\hline Incomplete Secondary & -7721.4 & -2.63 \\
\hline Secondary & -8551.9 & -2.35 \\
\hline University & -9397.2 & -1.28 \\
\hline No information & -6145 & -3.49 \\
\hline
\end{tabular}

Source: Authors' calculations based on ENIG data. 
Figure 1

Annual Consumer inflation in Colombia

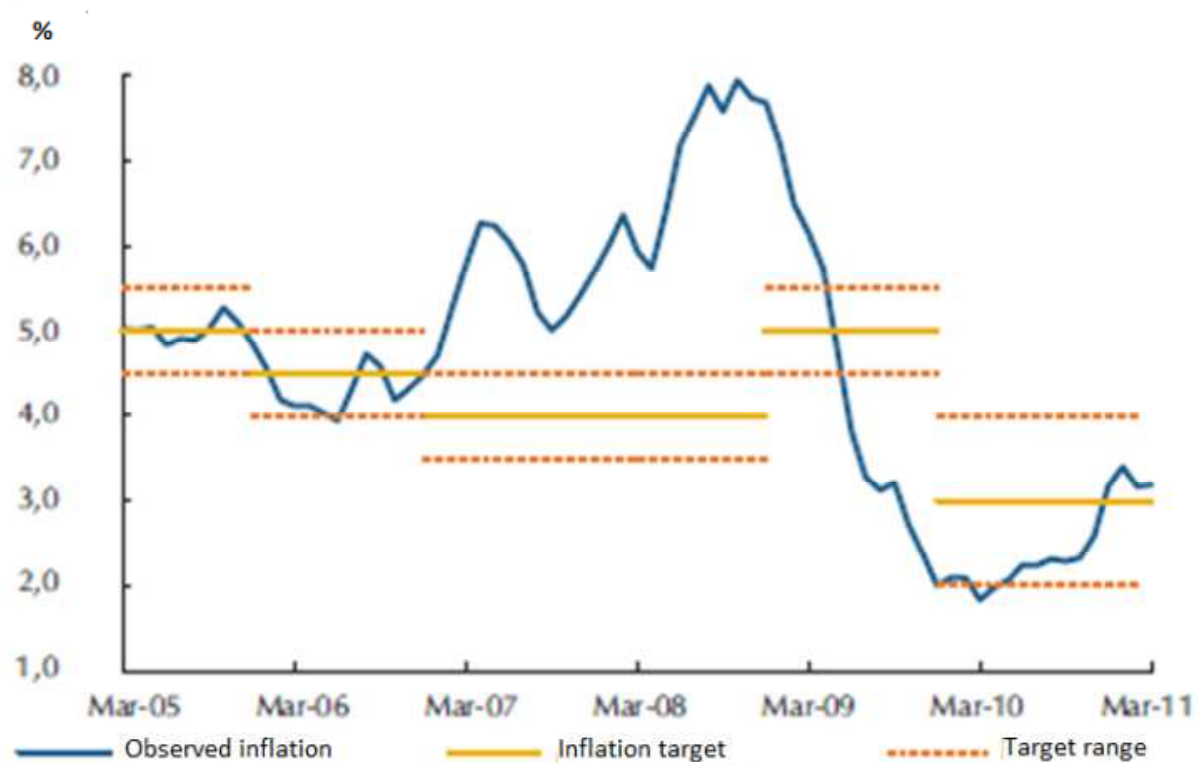

Source: BanRep, 2008 
Figure 2

Effects of price surges: proportional change of household welfare by cost of living Proportional change

by cost of living

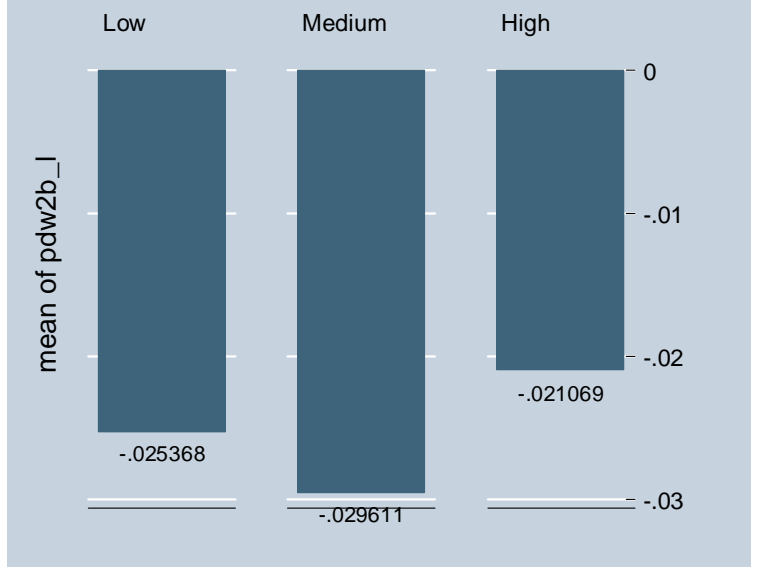

Source: Authors' calculations based on ENIG data. 
Figure 3

Effects of price surges: absolute changes by household expenditure quintile groups

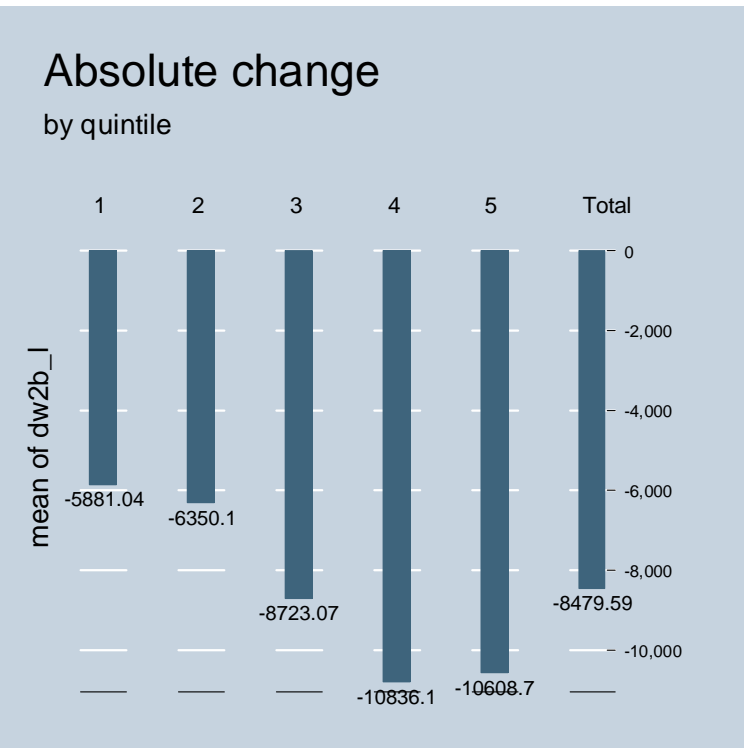

Source: Authors' calculations based on ENIG data 
Figure 4

Effects of price surges: proportional change by household expenditure quintile groups

\section{Porportional change}

by quintile

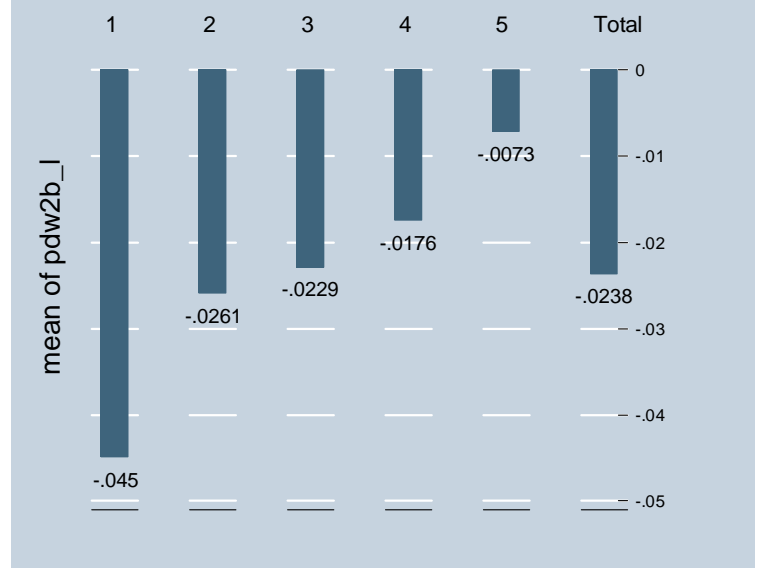

Source: Authors' calculations based on ENIG data 
Figure 5

Effects of price surges: proportional change of household welfare by the share of food expenditure in total household expenditure

\section{Proportional change}

by food share

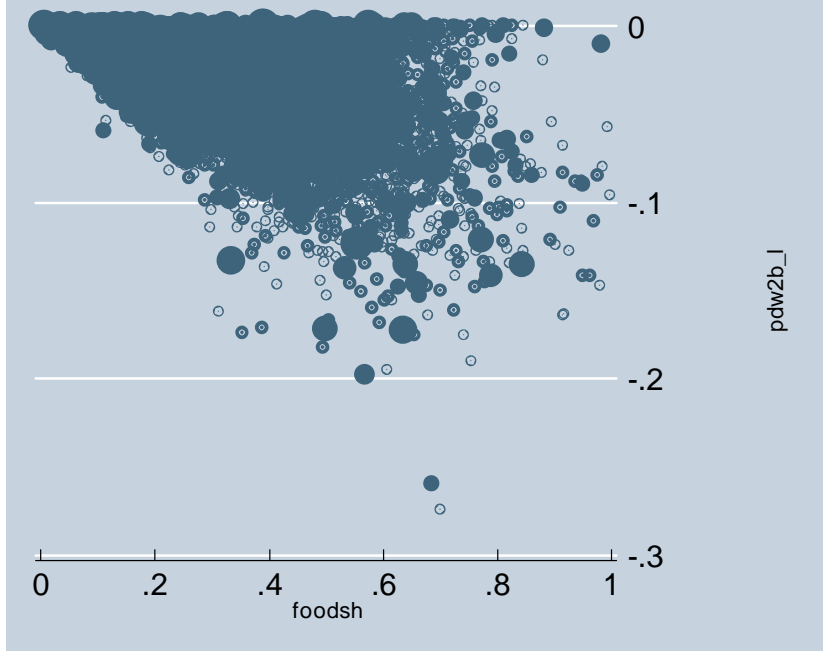

Source: Authors' calculations based on ENIG data. 
Figure 6.1

Changes of poverty headcount ratios by city, for moderate poverty

\section{Poverty head count}

Effect evolution by city

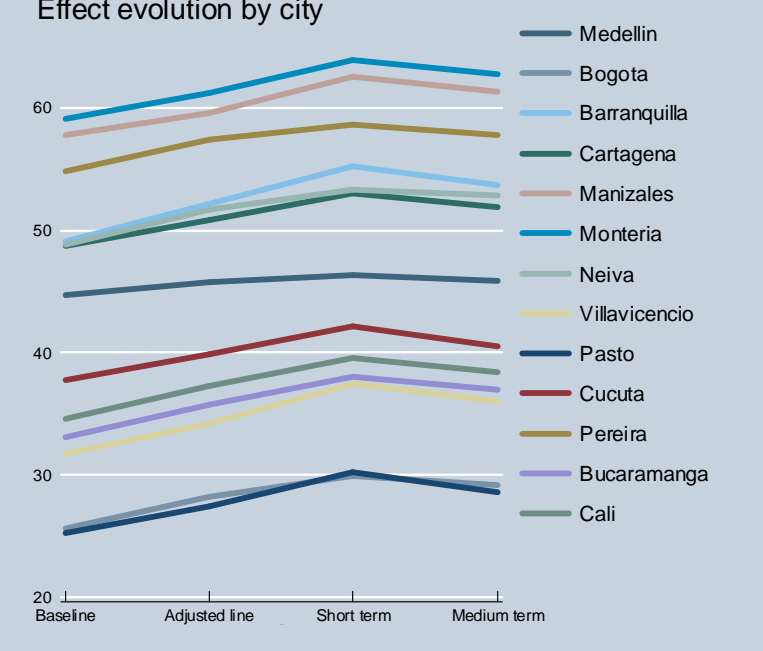

Source: Authors' calculations based on ENIG data. 
Figure 6.2

Changes of poverty headcount ratios by city, for extreme poverty

\section{Extreme poverty head count}

Effect evolution by city

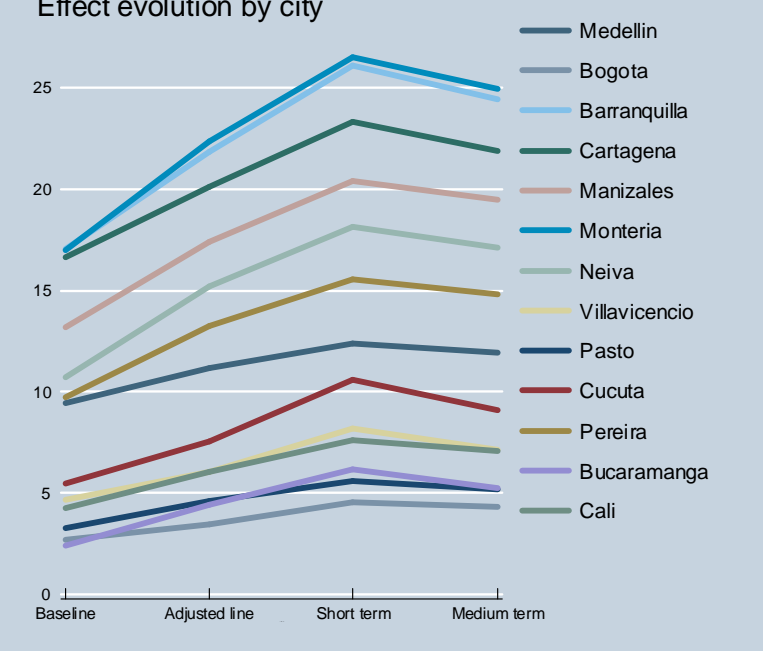

Source: Authors' calculations based on ENIG data. 
Figure 6.3

Changes of poverty gap by city, for moderate poverty

\section{Poverty gap}

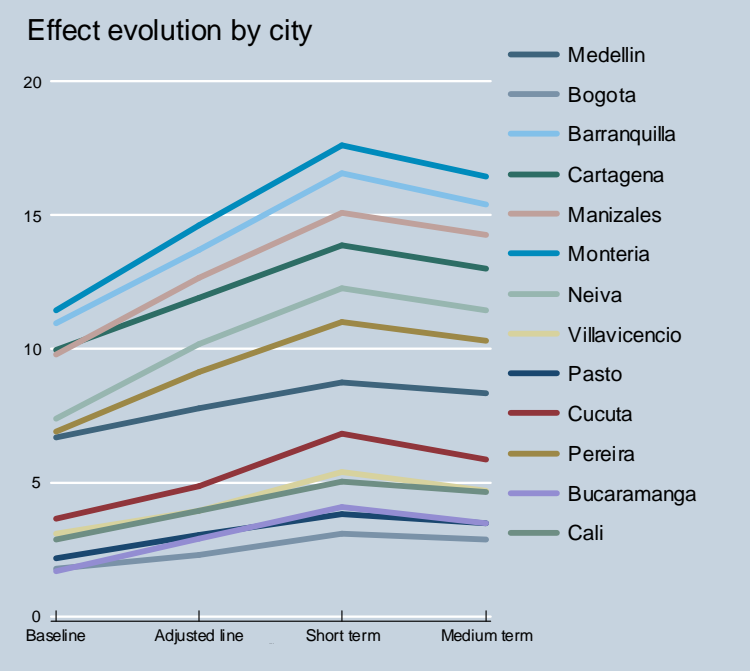

Source: Authors' calculations based on ENIG data. 


\section{Figure 6.4}

Changes of poverty gap by city, for extreme poverty

\section{Extreme poverty gap}

Effect evolution by city

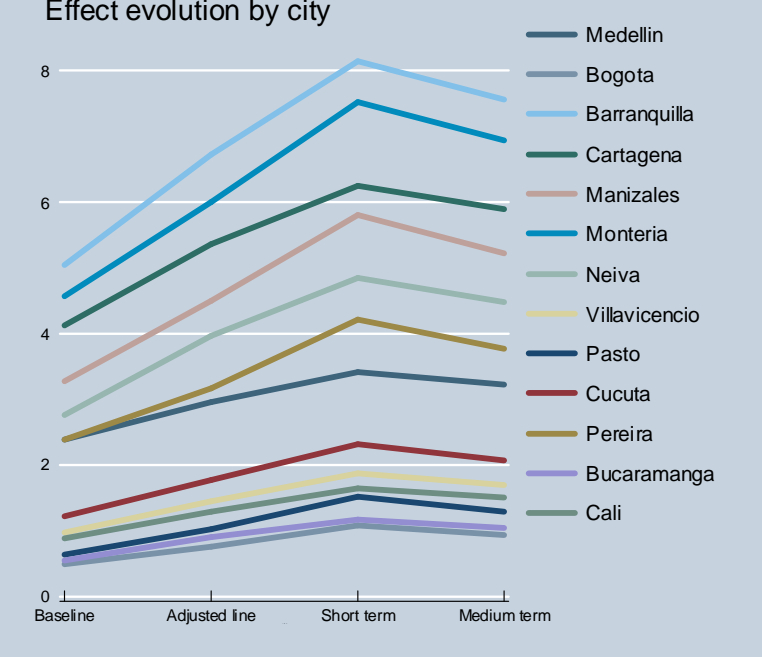

Source: Authors' calculations based on ENIG data. 


\section{Appendix}

Table A.1

Consumption -Summary

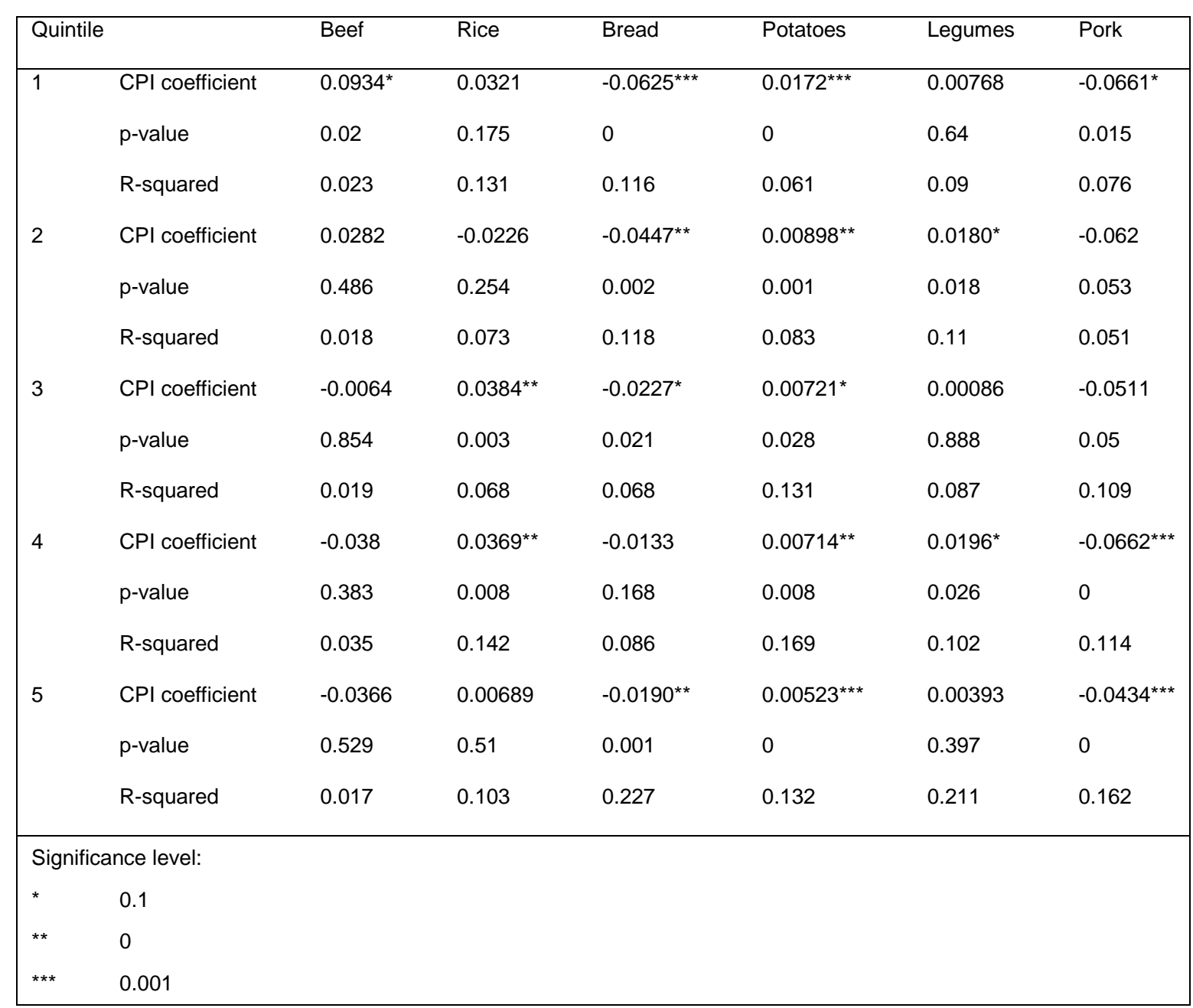


Table A.2

Consumption -Summary

\begin{tabular}{|c|c|c|c|c|c|c|c|c|}
\hline Quintile & & Chicken & Fish & Eggs & Milk & Oil & Sugar & Panela \\
\hline \multirow[t]{3}{*}{1} & CPI coefficient & 0.0282 & $-0.0388^{* *}$ & $0.0300^{* * *}$ & 0.0179 & -0.00738 & -0.0074 & $-0.0290^{\star * *}$ \\
\hline & $p$-value & 0.272 & 0.003 & 0 & 0.552 & 0.572 & 0.359 & 0 \\
\hline & R-squared & 0.086 & 0.083 & 0.107 & 0.081 & 0.081 & 0.113 & 0.208 \\
\hline \multirow[t]{3}{*}{2} & CPI coefficient & 0.0295 & $-0.0350^{\star * *}$ & 0.00791 & 0.00529 & $-1.39 \mathrm{E}-06$ & -0.0114 & $-0.0116^{\star * *}$ \\
\hline & $\mathrm{p}$-value & 0.312 & 0 & 0.119 & 0.796 & 1 & 0.068 & 0 \\
\hline & R-squared & 0.049 & 0.042 & 0.07 & 0.113 & 0.091 & 0.045 & 0.095 \\
\hline \multirow[t]{3}{*}{3} & CPI coefficient & -0.0141 & $-0.0266^{* *}$ & 0.00948 & 0.00026 & -0.0132 & 0.00065 & $-0.00959^{* *}$ \\
\hline & $\mathrm{p}$-value & 0.56 & 0.008 & 0.076 & 0.988 & 0.289 & 0.891 & 0 \\
\hline & R-squared & 0.093 & 0.055 & 0.09 & 0.101 & 0.046 & 0.059 & 0.134 \\
\hline \multirow[t]{3}{*}{4} & CPI coefficient & $0.0417^{\star}$ & -0.0098 & -0.0066 & 0.00601 & -0.0173 & 0.00313 & -0.0038 \\
\hline & $p$-value & 0.03 & 0.434 & 0.178 & 0.614 & 0.055 & 0.432 & 0.082 \\
\hline & R-squared & 0.083 & 0.108 & 0.096 & 0.09 & 0.068 & 0.056 & 0.086 \\
\hline \multirow[t]{3}{*}{5} & CPI coefficient & -0.0038 & -0.0168 & 0.0042 & -0.0101 & -0.0129 & 0.0019 & -0.0018 \\
\hline & $p$-value & 0.742 & 0.332 & 0.149 & 0.326 & 0.124 & 0.439 & 0.081 \\
\hline & R-squared & 0.186 & 0.157 & 0.176 & 0.152 & 0.099 & 0.118 & 0.132 \\
\hline \multicolumn{9}{|c|}{ Significance level: } \\
\hline * & 0.1 & & & & & & & \\
\hline ** & 0 & & & & & & & \\
\hline$* * *$ & 0.001 & & & & & & & \\
\hline
\end{tabular}


Table A.3

Price elasticities

\begin{tabular}{|c|c|c|c|c|c|c|c|c|c|c|c|c|c|}
\hline Quintile & Beef & Rice & Bread & Potatoes & Legumes & Pork & Chicken & Fish & Eggs & Milk & Oil & Sugar & Panela \\
\hline \multicolumn{14}{|l|}{ Levels } \\
\hline 1 & -0.366 & -0.693 & -1.906 & -0.591 & -0.866 & -1.802 & -0.683 & -1.572 & -0.47 & -0.823 & -1.123 & -1.202 & -1.7 \\
\hline 2 & -0.788 & -1.307 & -1.677 & -0.73 & -0.62 & -1.836 & -0.677 & -1.668 & -0.823 & -0.94 & -1 & -1.415 & -1.429 \\
\hline 3 & -1.048 & -0.336 & -1.331 & -0.776 & -0.98 & -1.81 & -1.162 & -1.508 & -0.765 & -0.997 & -1.296 & -0.975 & -1.498 \\
\hline 4 & -1.291 & -0.275 & -1.259 & -0.744 & -0.542 & -2.072 & -0.47 & -1.176 & -1.189 & -0.927 & -1.43 & -0.866 & -1.211 \\
\hline 5 & -1.289 & -0.814 & -1.382 & -0.766 & -0.889 & -1.887 & -1.051 & -1.34 & -0.855 & -1.137 & -1.416 & -0.889 & -1.181 \\
\hline \multicolumn{14}{|c|}{ Monthly variation } \\
\hline 1 & -0.998 & -1.029 & -1.008 & -0.997 & -1.004 & -0.998 & -0.993 & -0.999 & -1 & -1.002 & -0.986 & -1.01 & -1.008 \\
\hline 2 & -1.003 & -1.039 & -1.019 & -1 & -0.998 & -0.951 & -1.003 & -0.997 & -0.996 & -0.995 & -0.998 & -0.998 & -1.006 \\
\hline 3 & -0.999 & -1.002 & -0.994 & -0.994 & -1.002 & -0.999 & -1.01 & -0.982 & -1.002 & -0.991 & -1.031 & -0.993 & -1.006 \\
\hline 4 & -0.998 & -0.995 & -1.015 & -0.999 & -0.998 & -0.998 & -0.985 & -0.987 & -1.001 & -0.991 & -1.007 & -1.001 & -1.004 \\
\hline 5 & -1 & -1.004 & -0.992 & -0.998 & -0.999 & -1.017 & -0.986 & -0.99 & -1 & -0.995 & -1.001 & -1 & -1.003 \\
\hline \multicolumn{14}{|c|}{ Accumulated variation } \\
\hline 1 & -0.994 & -1.002 & -1.008 & -0.996 & -1.002 & -1.023 & -0.994 & -1.004 & -0.999 & -0.996 & -1.003 & -1 & -1.006 \\
\hline 2 & -0.998 & -1.005 & -1.009 & -0.997 & -0.999 & -1.011 & -0.981 & -0.997 & -1 & -1 & -1.004 & -1 & -1.006 \\
\hline 3 & -0.999 & -1 & -1.002 & -0.997 & -1 & -1.018 & -0.99 & -0.998 & -1 & -0.998 & -0.998 & -1 & -1.005 \\
\hline 4 & -1.001 & -1.001 & -1.002 & -0.997 & -0.997 & -1.019 & -1.003 & -0.999 & -1 & -0.999 & -1.001 & -1.001 & -1.004 \\
\hline 5 & -1.001 & -1 & -1.006 & -0.997 & -1.001 & -1.013 & -1.002 & -0.999 & -1.001 & -1.002 & -1.005 & -0.999 & -1.005 \\
\hline
\end{tabular}

